\title{
USE OF SURFACE MODIFIED BENTONITE CLAY CATALYST FOR ESTERIFICATION OF MALEIC ACID WITH ETHANOL
}

\author{
Rajkumar Sirsam ${ }^{1}$, Ghayas Usmani ${ }^{2}$ \\ ${ }^{1}$ Associate Professor, Department of Chemical Engineering, UICT, NMU, Jalgaon, MS, India \\ ${ }^{2}$ Professor, Department of Oil Technology, UICT, NMU, Jalgaon, MS, India
}

\begin{abstract}
Inorganic clays are being exploited as solid catalysts support for vide verity of organic reactions. Surface modified (SM) clay was synthesized by sulfuric acid treatment of raw bentonite clay. Acid treated clay was characterized by Fourier transform infrared spectroscopy (FTIR) and thermogravimetric analysis (TGA). The esterification of maleic acid with ethanol using SM clay catalyst was carried out to study an effect of various parameters viz. speed of agitation, catalyst loading, mole ratio of reactants and temperature. SM bentonite shows better catalytic activity towards maleic acid-ethanol esterification. A Pseudo-homogeneous kinetic model was used to validate the experimental data. Kinetic parameter such as rate constant and activation energy was estimated for the reaction.
\end{abstract}

Keywords: Esterification, maleic acid, SM bentonite, rate constant, activation energy.

\section{INTRODUCTION}

In many organic synthesis homogeneous catalysts such as $p$ TSA, sulfuric acid, phosphoric acid, perchloric acid etc. were extensively used and have several disadvantages. These catalysts are being replaced by solid catalysts such as cation-exchange resin, zeolites, metal oxides, acid treated clays etc, which improves the economics of the process and also eco-friendly in nature [1-4].

In verity of organic reactions inorganic clays attracted the researches attention to use it as catalyst support [5-6]. Surface modifications of clays are performed in-order to improve the acidity of clay matrix which can be achieved by acid activation of clays [7]. Improvement of catalytic activity of raw clay exclusively depends upon the acid treatment conditions applied [8-11]. SM clays were used as catalysts for esterification [12, 13], adsorbent [14-17].

Organic esters are widely used as solvents, plasticisers, as a intermediate in many organic synthesis and in the manufacture of many fine chemicals. Maleate esters are used as an intermediate in organic synthesis and can be synthesized by treating maleic anhydride [1, 19-23] or maleic acid [18] with ethanol. Jaung H. M. [23] has reported the preparation of diethyl maleate by esterification of maleic anhydride by using homogeneous catalyst $p$-tolune sulfonic acid. Yadav G. D. [18] had carried out the extensive kinetic study for the esterification of maleic acid with ethanol over various cation exchange resins.

The primary objective in this article is to modify the surface of inorganic clay (bentonite), characterization and application of SM clay for the esterification of maleic acid with ethanol.

\section{EXPERIMENTAL}

\subsection{Chemicals}

All the chemicals used for the experiment were of reputed company. Bentonite and maleic acid were purchased from $\mathrm{s}$. d. fine chemicals. Ethanol, potassium hydroxide was obtained from Meark. All the chemicals were used as received without any purification. Solutions were prepared in double distilled water, whenever required.

\subsection{Synthesis of SM Clays}

In the typical synthesis of SM clay, 100 gm of clay sample was slurred with $1000 \mathrm{ml}$ water and allowed to be swell overnight at room temperature. $30 \mathrm{gm}$ of concentrated sulfuric acid (98\%), acid to clay ratio on weight basis 0.3 , was added slowly drop by drop to the clay-water slurry. The resulting mixture was kept in constant temperature bath at $90{ }^{\circ} \mathrm{C}$ for $16 \mathrm{hr}$. The slurry was continuously stirred at about $200 \mathrm{rpm}$ by overhead stirrer. Regularly the $\mathrm{pH}$ of the mixture was checked and maintained constant at 2. At the end of the stirring, $1000 \mathrm{ml}$ chilled water has been added to stop the reaction $[12,13]$.

The resulting slurry was washed several times with hot double distilled water in centrifuge (RIMI modal) until it becomes free of $\mathrm{SO}_{4}{ }^{2-}$ ions. $\mathrm{BaCl}_{2}$ test has been conducted to ensure the slurry is free of $\mathrm{SO}_{4}{ }^{2-}$ ions. The resulting acid activated clay was dried overnight at $110{ }^{\circ} \mathrm{C}$ and ground to a fine powder.

Acid activated clay (50 gm) was added to $2000 \mathrm{ml}$ aqueous solution of hydrochloric acid $(0.5 \mathrm{M})$. Predetermined solution to clay ratio of $40 \mathrm{ml} / \mathrm{gm}$ of clay was maintained. Protonation of acid activated clay was then conducted at room temperature for $18 \mathrm{hr}$ with constant stirring. At the end of the process, the resulting slurry was washed several times 
with double distilled water in RIMI centrifuge. $\mathrm{AgNO}_{3}$ test was conducted to ensure that the clay is free of $\mathrm{Cl}^{-}$ions. The resulting solid was dried overnight at $110^{\circ} \mathrm{C}$ in an oven and then ground to fine powder.

\subsection{Experimental Procedure}

Batch experiments were carried out in a mechanically agitated reactor $2.5 \times 10^{-4} \mathrm{~m}^{3}$ capacity provided with reflux condenser immersed in constant temperature bath. Maleic acid (0.171 moles) and ethanol (0.857 moles) were taken into reactor and allowed to attend reaction temperature and then catalyst $\left(120 \mathrm{~kg} / \mathrm{m}^{3}\right)$ was added to reaction mixture. The samples were withdrawn and analyzed chemically as well as by Gas chromatography at specific interval of time.

\subsection{Analysis}

Fractional conversion of maleic acid was estimated by chemical and gas chromatographic analysis. Chemical analysis was carried out by titration of reaction mixture sample with alcoholic KOH. Details of gas chromatography analysis are listed in table 1.

Table -1: Details of gas chromatography analysis

\begin{tabular}{|l|l|}
\hline GC system & $7890 \mathrm{~B}$ Agilent Technologies \\
\hline Column & $\begin{array}{l}\mathrm{HP}-5 \% \text { capillary column }(30 \mathrm{~m} ; \\
320 \mu \mathrm{m} ; 0.25 \mu \mathrm{m})\end{array}$ \\
\hline $\begin{array}{l}\text { Injection } \\
\text { temperature }\end{array}$ & $250^{\circ} \mathrm{C}$ \\
\hline $\begin{array}{l}\text { Detector (FID) } \\
\text { temperature }\end{array}$ & $300{ }^{\circ} \mathrm{C}$ \\
\hline Oven temperature & $\begin{array}{l}150{ }^{\circ} \mathrm{C}, 270{ }^{\circ} \mathrm{C} \text { @ } 10^{\circ} \mathrm{C} / \mathrm{min} \text { hold } \\
\text { for } 7 \mathrm{~min} .\end{array}$ \\
\hline Carrier gas & Nitrogen \\
\hline Flow rate & $3.19 \mathrm{ml} / \mathrm{min}$ \\
\hline
\end{tabular}

\section{RESULTS AND DISCUSSION}

\subsection{Characterization of IE Clays}

\subsubsection{FTIR Analysis}

Figure 1 shows the FTIR spectra of raw and modified clay. Samples were dried at $100{ }^{\circ} \mathrm{C}$ before FTIR analysis to remove weakly adsorbed species. The characteristic band in the range of $3100-3700 \mathrm{~cm}^{-1}$ assigned to stretching frequency of $-\mathrm{OH}$ group of freely bounded water on clay surface $[24,25]$. The band in the range of $2800-2900 \mathrm{~cm}^{-1}$ observed in modified clays which corresponds to -C-Hstretching vibration [24]. This confirms the modification of surface occurs by means of acid treatment. In FTIR spectra of SM bentonite, the characteristic band at $1545 \mathrm{~cm}^{-1}$ shows Bronsted acidic sites and band at $1488 \mathrm{~cm}^{-1}$ shows the contribution of both Lewis and Bronsted acidic sites [25, 26]. The Si-O-Si linkage stretching vibration on unmodified bentonite surface was observed at $1632 \mathrm{~cm}^{-1}$ which has been shifted to $1641 \mathrm{~cm}^{-1}$ in modified bentonite clay. This shifting of band clearly indicated that the interaction of clay with sulfuric acid. The band at $1001 \mathrm{~cm}^{-1}$ attributed to Si-O stretching frequency in raw bentonite has shifted to higher wavenumber $1031 \mathrm{~cm}^{-1}$ with additional shoulder peak at $1009 \mathrm{~cm}^{-1}$ in modified bentonite $[16,24]$.

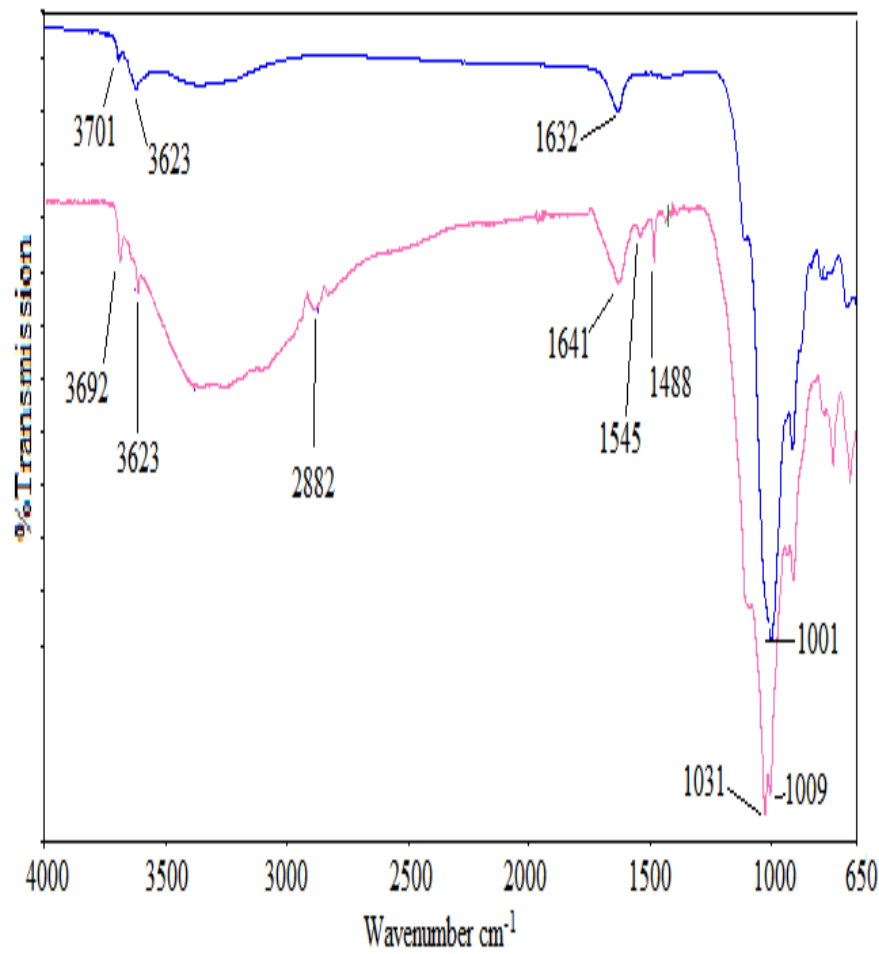

Fig 1: FTIR spectra for (a) Bentonite, (b) SM bentonite.

\subsubsection{Thermogravimetric Analysis (TGA)}

Figure 2 shows the TGA of raw and modified clays. All the samples were dried at $110{ }^{\circ} \mathrm{C}$ overnight before analysis. The measurements were carried out in the range of $30-800{ }^{\circ} \mathrm{C}$ at heating rate of $10{ }^{\circ} \mathrm{C} / \mathrm{min}$. TGA curve of bentonite shows sharp weight loss of about $8 \%$ below $100{ }^{\circ} \mathrm{C}$ due to dehydration, which corresponds to the removal of physically adsorbed water from the surface, whereas in case of SM Bentonite it shows only $4 \%$ loss. This minor weight loss in the temperature range of dehydration step implies the changes in the thermal stability of modified bentonite [13, 27]. There was negligible weight loss upto $400{ }^{\circ} \mathrm{C}$ due to hydroxyl water associated with parent clay structure. Gradual weight loss was observed for modified bentonite in the range of $100-400{ }^{\circ} \mathrm{C}$ which corresponds to hydroxyl water and sulfonic acid group [13, 28]. Additional amount of chemisorbed water was lost during $400-650{ }^{\circ} \mathrm{C}$ present in the structure [28] and gradual weight loss of about $4 \%$ in the range of 350 to $675^{\circ} \mathrm{C}$ due to additional amount of water present between the layers of the clay [12]. Maximum weight loss was observed at about $450{ }^{\circ} \mathrm{C}$, this weight loss was due to additional amount of water and organic moieties incorporated onto the clay structure during the acid treatment. The changes in the decomposition pattern of parent bentonite support the interaction of clay structure with sulphuric acid. 


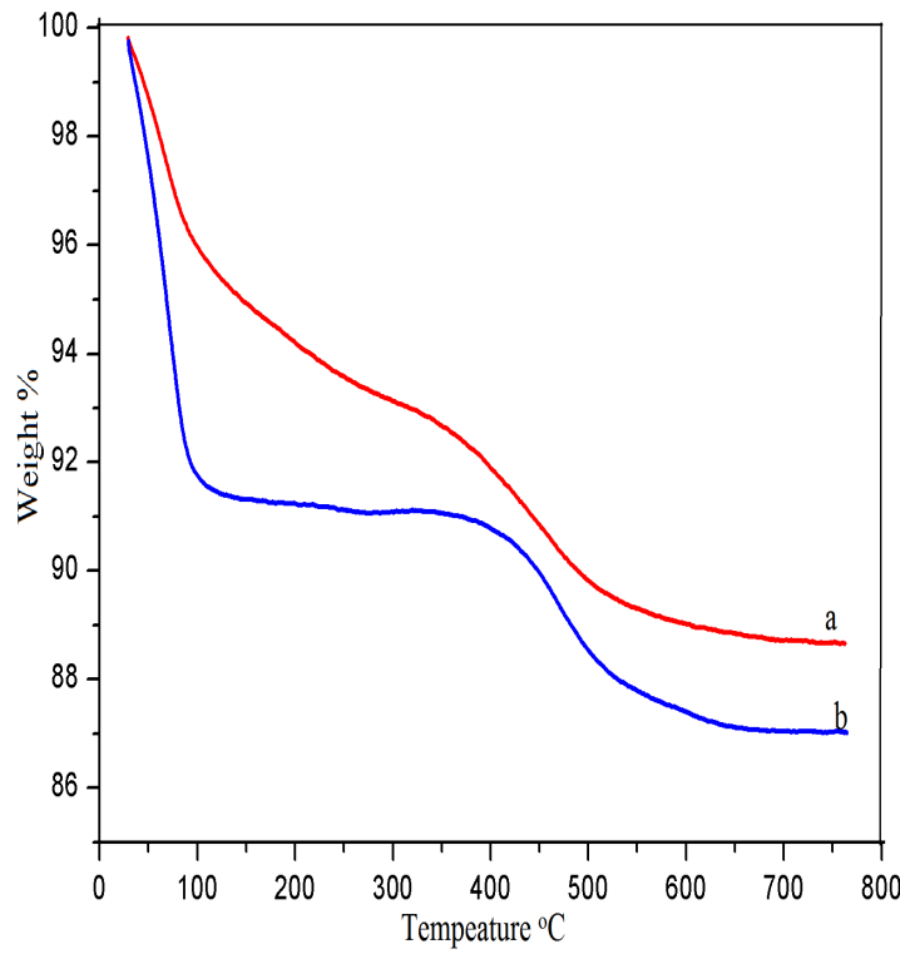

Fig 2: Thermogravimetric analysis for (a) SM Bentonite, (b) raw Bentonite.

\subsection{Kinetic Model}

The esterification of maleic acid with ethanol in presence of catalyst can be represented as follows:

$$
\begin{aligned}
& \mathrm{HCOOCH}-\mathrm{CHCOOH}+2 \mathrm{C}_{2} \mathrm{H}_{5} \\
& \mathrm{C}_{2} \mathrm{H}_{5} \mathrm{COOCH}-\mathrm{CHCOOC} \mathrm{H}_{5}+2 \mathrm{H}_{2} \mathrm{O}
\end{aligned}
$$

The esterification maleic acid with etahnol assumed to be occurred in two steps (Eq. 1), formation of monoester and reaction of monoester with another ethanol molecule to form diethyl maleate. The first step assumed to be faster as compare to latter [3]. The concentration of ethanol during the reaction was kept in excess to shift the equilibrium towards the formation of product.

Yadav (2002) [18] reported a pseudo homogeneous model for the kinetic study of esterification of maleic acid with ethanol over various cation exchange resins. As the experiments were conducted under similar conditions except catalyst, same model was used to validate the experimental data and calculation of kinetic parameters. Table 2 describes the summery of rate constants evaluated for different runs. The kinetic model is as below:

$$
\frac{2}{(M-2)}\left[\begin{array}{l}
\frac{1}{(M-2)} \ln \left\{\frac{M}{\left(M-2 X_{A}\right)}\right\}-\frac{1}{(M-2)} \\
\times \ln \left(1-X_{A}\right)-\frac{2 X_{A}}{\left(M-2 X_{A}\right)}
\end{array}\right]
$$$$
=w k_{1} C_{A 0} t=k^{\prime} t
$$

Where $\mathrm{M}, X_{A}, C_{A 0}, w$ and $k_{1}$ is mole ratio (ethanol to maleic acid), fractional conversion of maleic acid, weight of catalyst, initial concentration of maleic acid and rate constant respectively.

Table -1: Evaluated rate constant from pseudohomogeneous model.

\begin{tabular}{|l|l|}
\hline Operating Condition & Rate Constant \\
\hline${ }^{\mathrm{a}}$ Temperature $\left({ }^{\circ} \mathrm{C}\right)$ & $\left(\mathrm{m}^{3} / \mathrm{kmol} . \mathrm{kg} . \mathrm{s}\right)$ \\
50 & $3.680 \times 10^{-9}$ \\
60 & $8.465 \times 10^{-9}$ \\
70 & $1.769 \times 10^{-8}$ \\
80 & $2.476 \times 10^{-8}$ \\
\hline${ }^{\mathrm{b}}$ Catalyst Loading $\left(\mathrm{kg} / \mathrm{m}^{3}\right)$ & \\
50 & $1.766 \times 10^{-8}$ \\
80 & $2.114 \times 10^{-8}$ \\
120 & $2.476 \times 10^{-8}$ \\
\hline
\end{tabular}

${ }^{a}$ Catalyst:SM Bentonite, Speed: $1000 \mathrm{rpm}$, Mole ratio: 1:5, Cat. Loading: $120 \mathrm{~kg} / \mathrm{m}^{3}$

b Catalyst:SM Bentonite, Speed: $1000 \mathrm{rpm}$, Mole ratio: 1:5, Temperature: $80{ }^{\circ} \mathrm{C}$.

\subsection{Catalyst Study}

Catalytic activity of SM bentonite was investigated for the esterification of maleic acid with ethanol. The reaction was carried out in a batch reactor as mentioned earlier. Based on the reaction mixture volume $120 \mathrm{~kg} / \mathrm{m}^{3}$ of catalyst was employed for maleic acid to ethanol mole ratio of 1:5. The reaction was carried out at $80{ }^{\circ} \mathrm{C}$ at $1000 \mathrm{rpm}$. Fig. 3 shows the fractional conversion of maleic acid with time for SM bentonite as a catalyst. It has been observed that after 120 min there was no significant change in fractional conversion of maleic acid hence all further experiments were conducted for three hours.

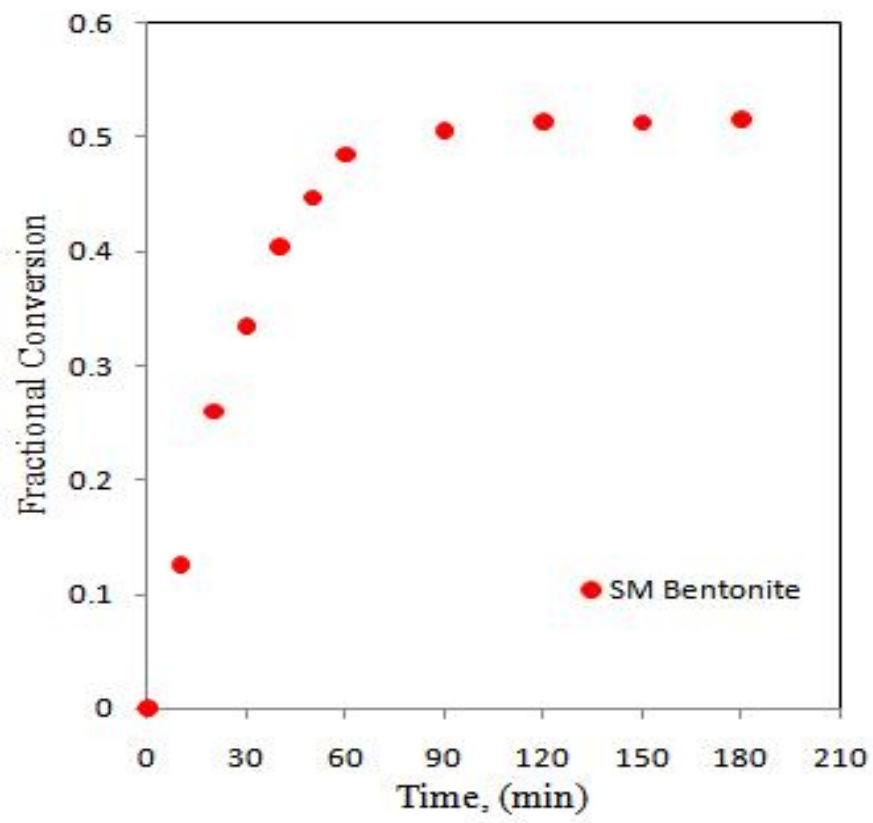

Fig. 3: Catalytic activity of SM Bentonite: temperature $80^{\circ} \mathrm{C}$, Speed $1000 \mathrm{rpm}$, Catalyst loading $120 \mathrm{~kg} / \mathrm{m}^{3}$, mole ratio (maleic acid to ethanol) 1:5. 


\subsection{Effect of Speed of Agitation}

To study the effect of speed of agitation on the conversion, speed was varied from $500-1000 \mathrm{rpm}$. Similar reaction condition was maintained as mentioned earlier except the speed of agitation. It was observed that there is no significant change in the fractional conversion of maleic acid (Fig. 4) and hence all the further experiments were conducted at $1000 \mathrm{rpm}$.

\subsection{Effect of Catalyst Loading}

Catalyst loading was varied from 50 to $120 \mathrm{~kg} / \mathrm{m}^{3}$ based on the reaction mixture volume under otherwise similar conditions (Fig. 5). As the catalyst loading increases the active sites available for reaction increases and consequently the conversion of maleic acid increases. At higher catalyst loading the rate of mass transfer of reactant from the bulk of liquid to solid surface is high and conversion increases proportionally [18]. It was observed at higher catalyst loading there was reasonable change in the conversion of maleic acid. Experimental data obtained for different catalyst loading was validated using kinetic model. LHS of Eq. (2) was plotted against time $t$ (Fig. 6), which shows the straight line passing through the origin with slope " $k$ "'. The value of " $\boldsymbol{k}$ " " for different catalyst loading plotted against weight of catalyst $w, \mathrm{~kg} / \mathrm{m}^{3}$ (Fig. 7), which gives straight line with $R^{2}=0.971$ and this supports that adopted kinetic model can be used to validate the experimental data.

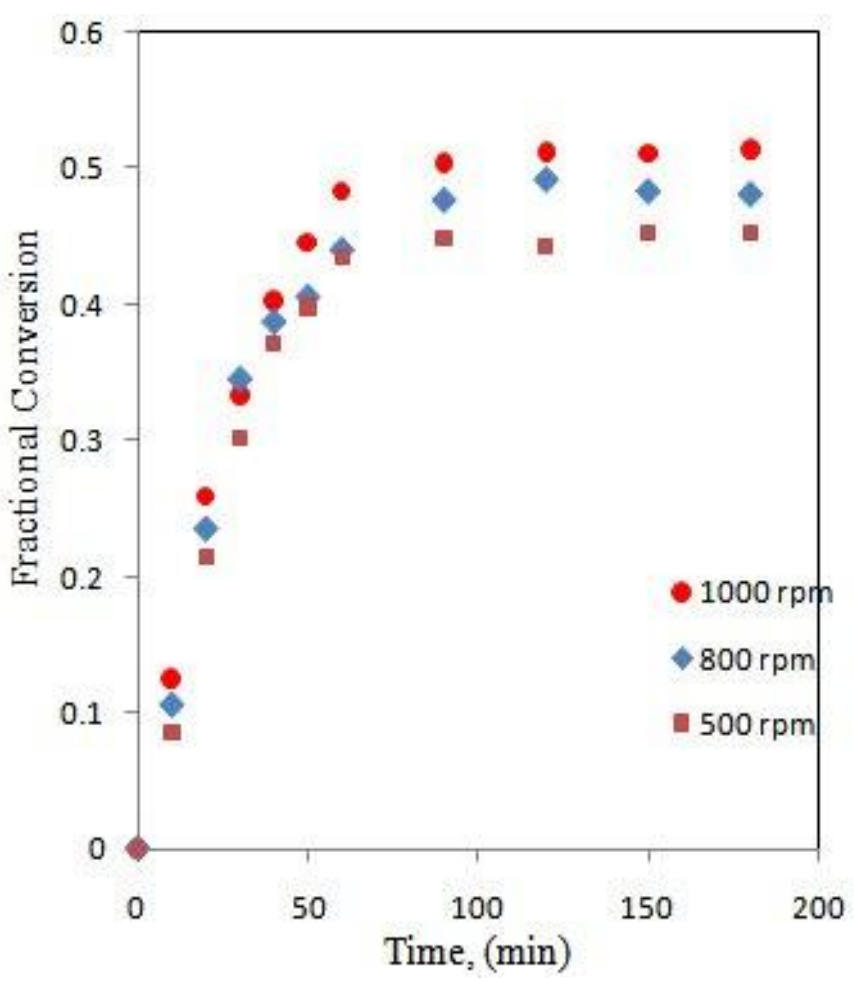

Fig. 4: Effect of speed of agitation: Temperature $80{ }^{\circ} \mathrm{C}$, Catalyst loading $120 \mathrm{~kg} / \mathrm{m}^{3}$, mole ratio (maleic acid to ethanol) 1:5, Catalyst- SM Bentonite.

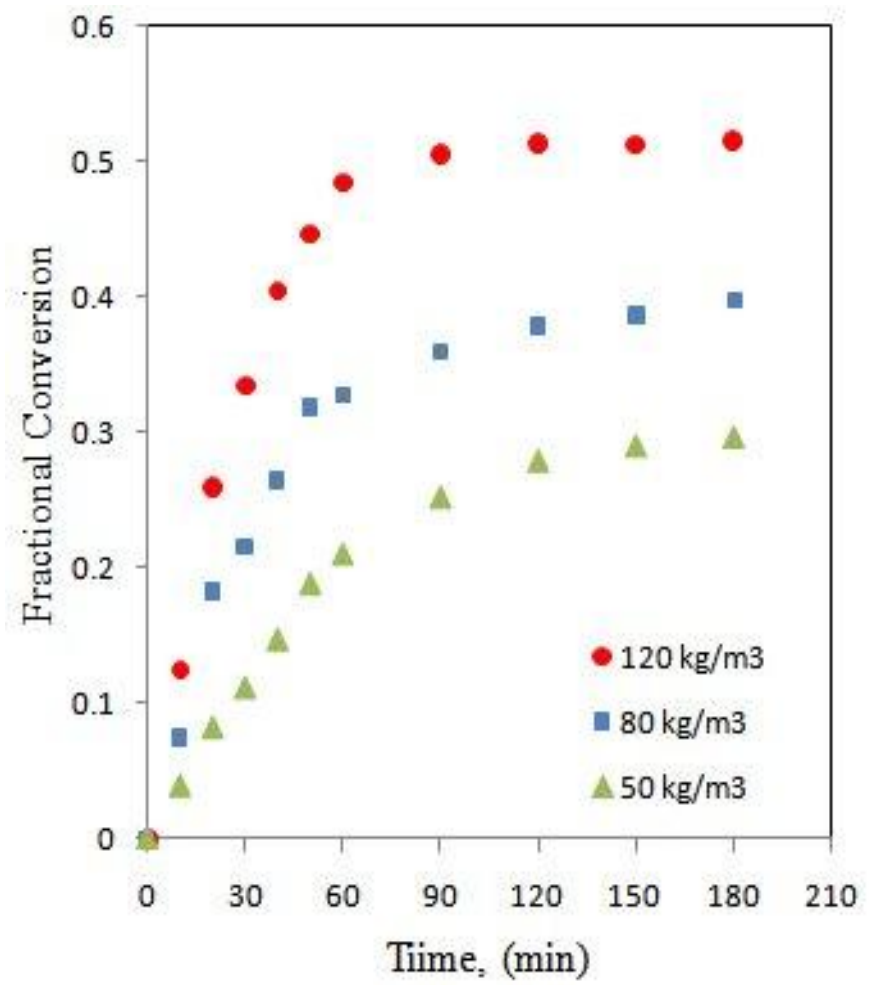

Fig. 5: Effect of Catalyst loading: Temperature $80{ }^{\circ} \mathrm{C}$, Speed of agitation $1000 \mathrm{rpm}$, mole ratio (maleic acid to ethanol) 1:5, Catalyst- SM Bentonite.

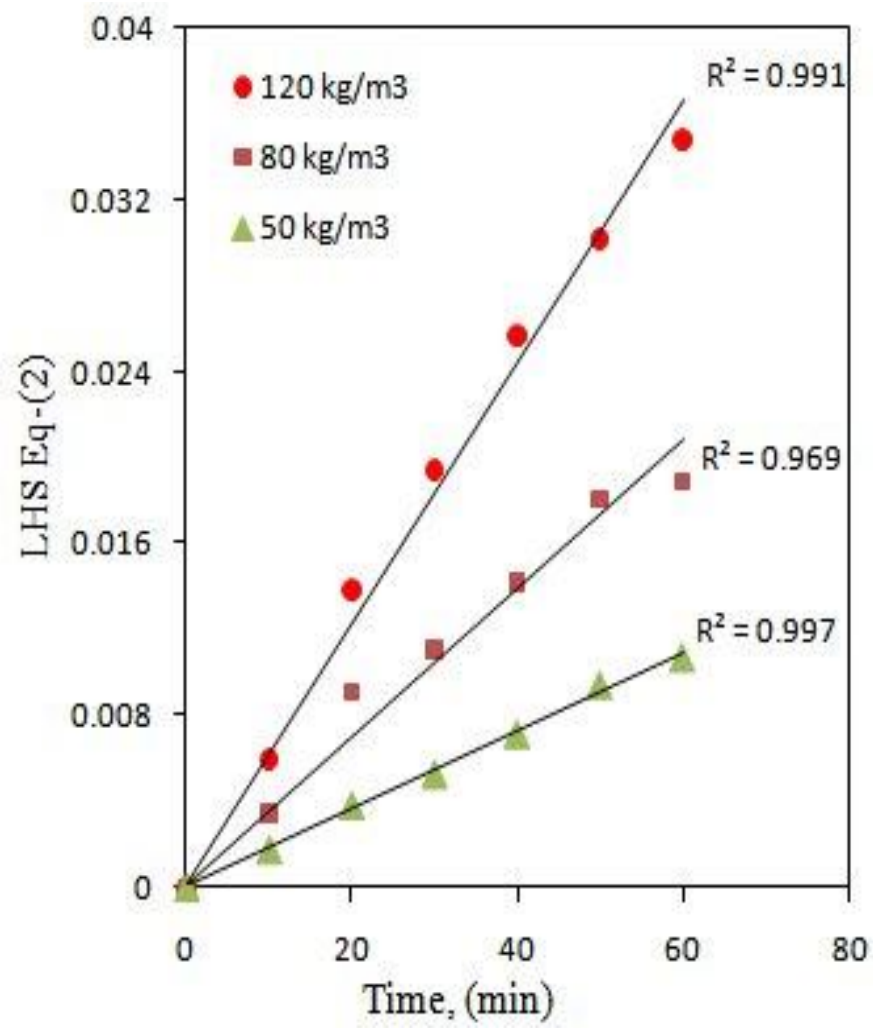

Fig 6: Kinetic plot for Catalyst loading: Temperature $80{ }^{\circ} \mathrm{C}$, Speed of agitation $1000 \mathrm{rpm}$, mole ratio (maleic acid to ethanol) 1:5, Catalyst- SM Bentonite. 


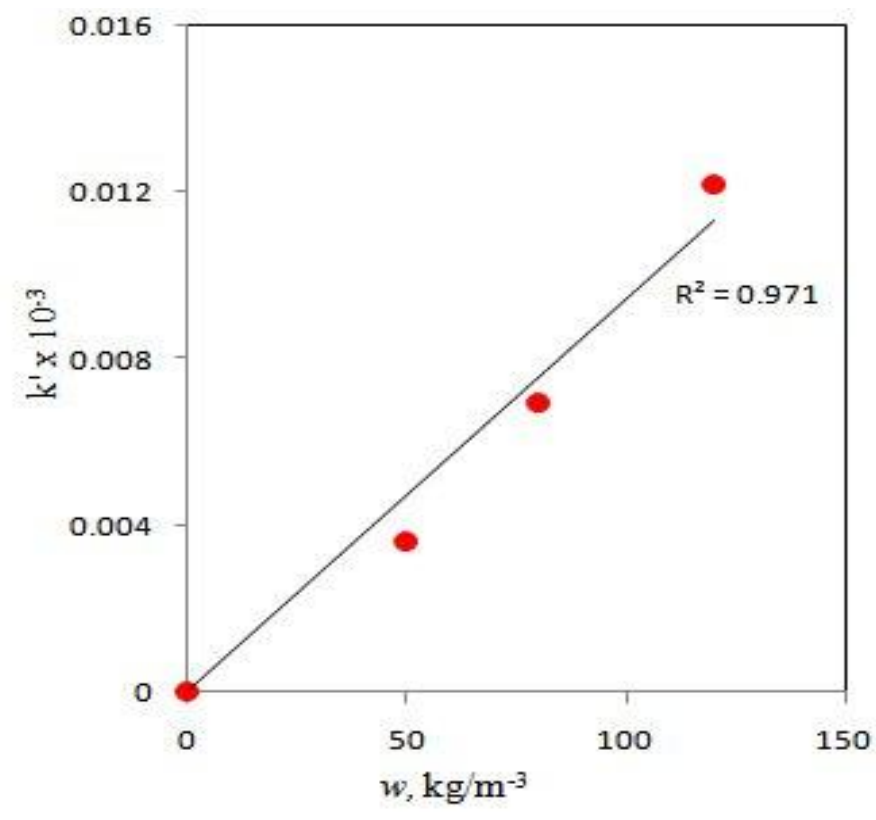

Fig. 7: Graph of k' v/s catalyst loading: Temperature $80{ }^{\circ} \mathrm{C}$, Speed of agitation $1000 \mathrm{rpm}$, mole ratio (maleic acid to ethanol) 1:5, Catalyst- SM Bentonite.

\subsection{Effect of Mole Ratio of Reactants}

Ethanol was taken in far excess to shift the equilibrium towards the formation of diethyl maleate. The limiting reactant maleic acid ( 0.172 mole $)$ and desired amount of ethanol was taken in excess to study the effect of mole ratio. The mole ratio maleic acid:ethanol was varied from 1:5 to $1: 15$. It was observed that as the amount of ethanol increases reaction shifts towards the product side. There was no significant change in conversion of maleic acid for mole ratio of 1:10 and 1:15 (Fig. 8) Again the experimental data for mole ratio was plotted using Eq. (2) (Fig. 9) and it was found that experimental data fits the kinetic model well

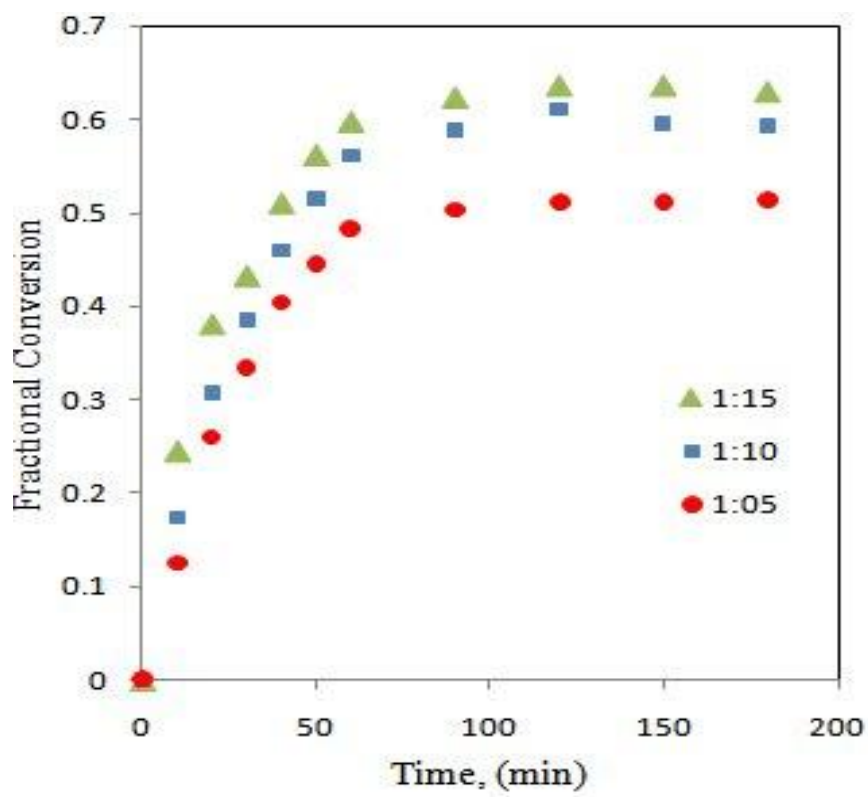

Fig. 8: Effect of mole ratio maleic acid to ethanol: Temperature $80^{\circ} \mathrm{C}$, Speed of agitation $1000 \mathrm{rpm}$ Catalyst loading $120 \mathrm{~kg} / \mathrm{m}^{3}$, Catalyst- SM Bentonite

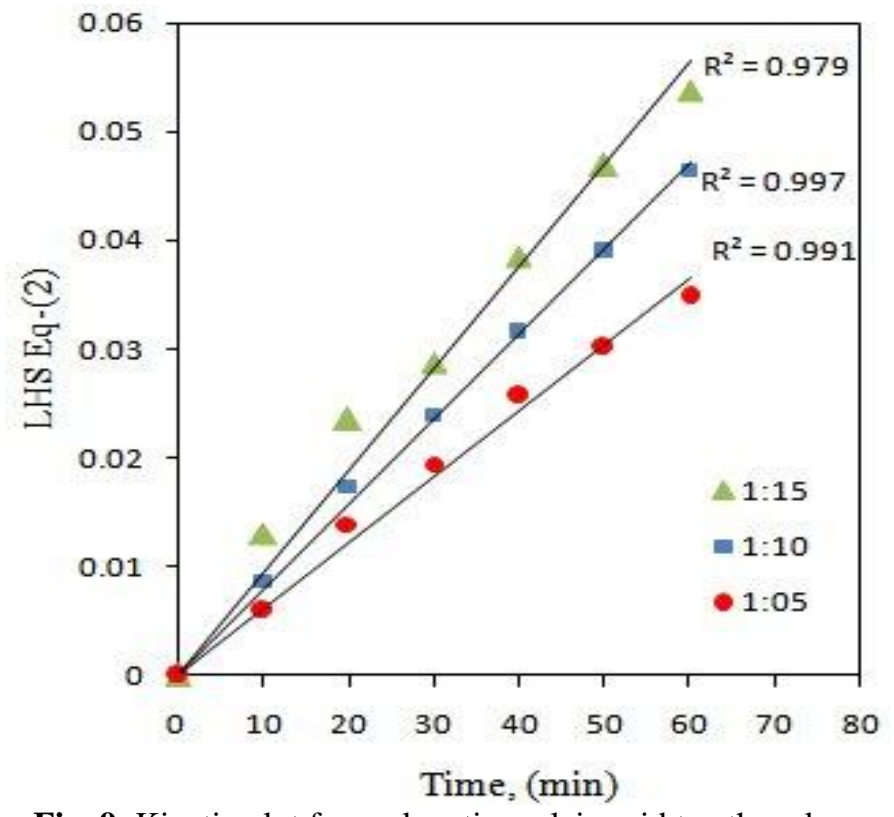

Fig. 9: Kinetic plot for mole ratio maleic acid to ethanol: Temperature $80^{\circ} \mathrm{C}$, Speed of agitation $1000 \mathrm{rpm}$ Catalyst loading $120 \mathrm{~kg} / \mathrm{m}^{3}$, Catalyst- SM Bentonite.

\subsection{Effect of Temperature}

The effect of temperature on the rate of reaction was investigated in the range of 50 to $80{ }^{\circ} \mathrm{C}$. It was observed that the conversion of maleic acid increases with increase in temperature (Fig. 10). Kinetic model Eq. (2) was plotted to determine the rate constant for the system. From fig 11 suggest that the adopted kinetic model reasonably represents the system in the temperature range $50-80{ }^{\circ} \mathrm{C}$. From the slope of the straight line the value of rate constant $k_{l}$ was calculated. The Arrhenius equation was used to determine the activation energy of the reaction for modified bentonite catalyst (Fig. 12). The activation energy was found to be $14.68 \mathrm{kcal} / \mathrm{mol}$.

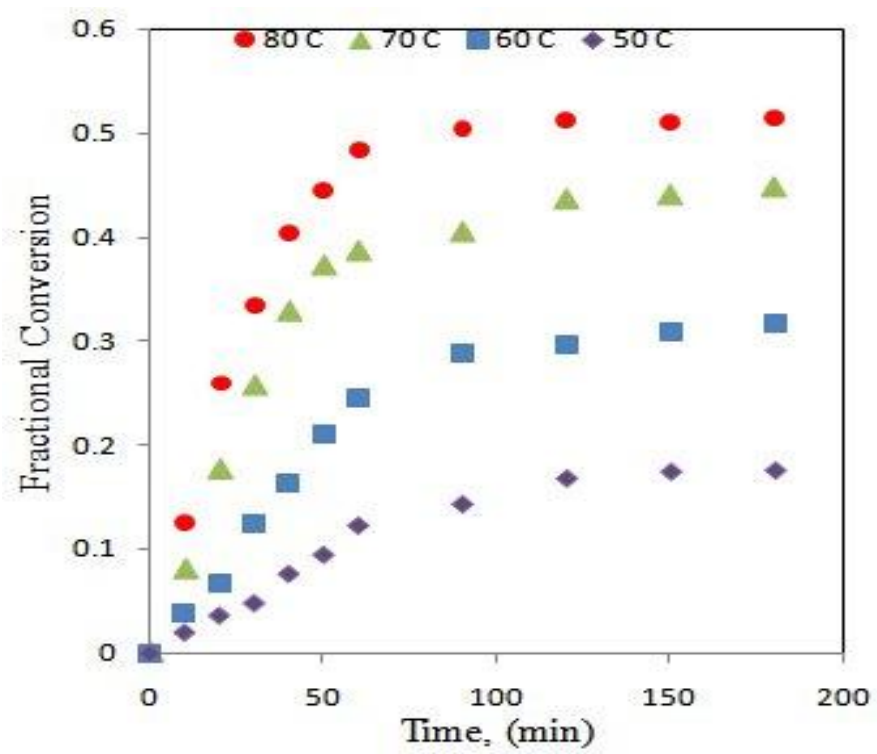

Fig. 10: Effect of temperature: Speed of agitation $1000 \mathrm{rpm}$, mole ratio (maleic acid to ethanol) 1:5, Catalyst loading 120 $\mathrm{kg} / \mathrm{m}^{3}$, Catalyst- SM Bentonite. 


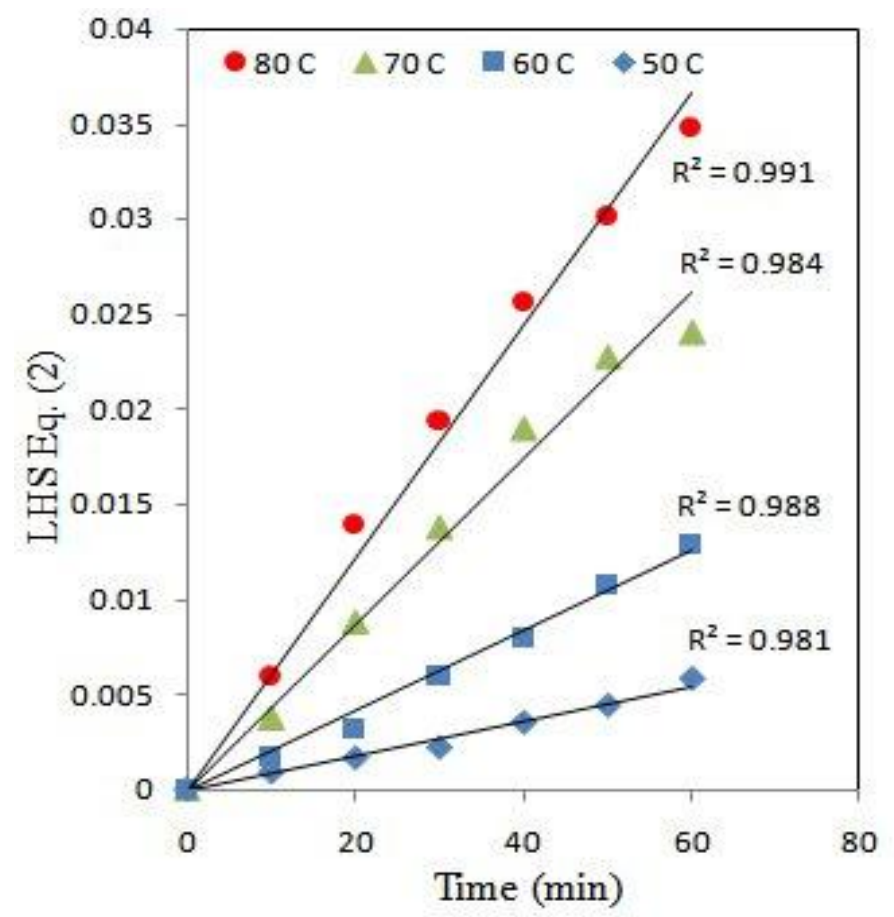

Fig. 11: Kinetic plot for temperature: Speed of agitation $1000 \mathrm{rpm}$, mole ratio (maleic acid to ethanol) 1:5, Catalyst loading $120 \mathrm{~kg} / \mathrm{m}^{3}$, Catalyst- SM Bentonite.

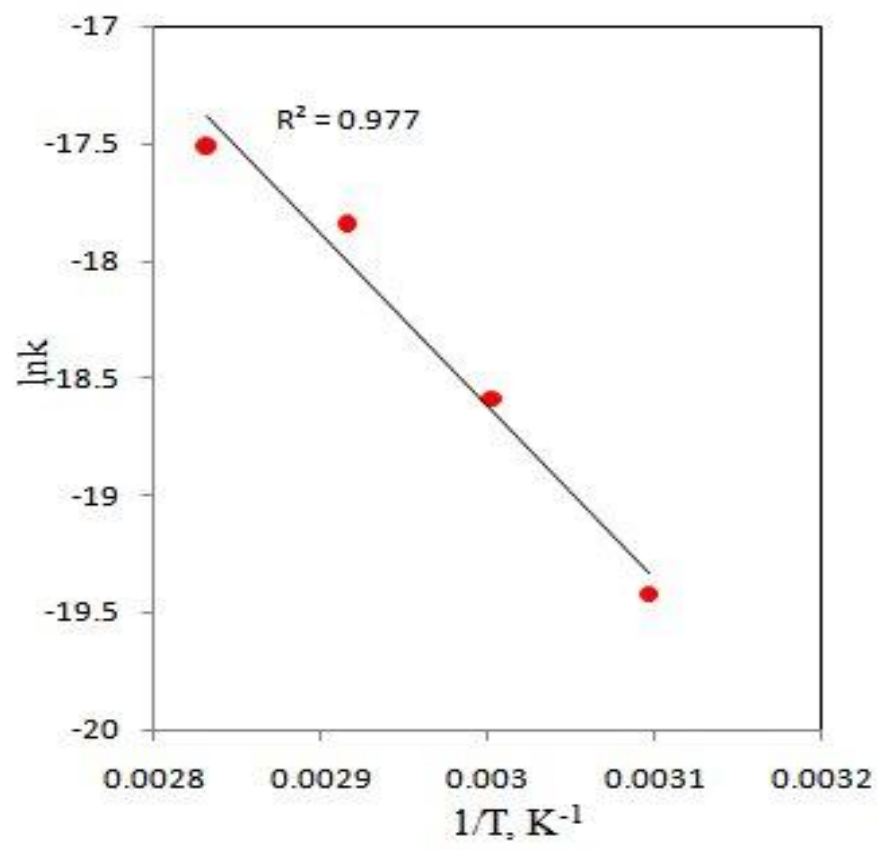

Fig. 12: Arrhenius plot of lnk v/s 1/T: Speed of agitation $1000 \mathrm{rpm}$, mole ratio (maleic acid to ethanol) 1:5, Catalyst loading $120 \mathrm{~kg} / \mathrm{m}^{3}$, Catalyst- SM Bentonite.

\section{CONCLUSION}

The surface of inorganic clay bentonite was modified by acid treatment and surface modification was confirmed by characterization using FTIR and TGA. Surface modified clay was used as catalyst for the esterification of maleic acid with ethanol. SM bentonite shows better catalytic activity. Experimental data for various parameters were validated by pseudo-homogeneous kinetic model. Rate constant for reaction at different operating conditions were calculated and activation energy of reaction was found to be 14.68 $\mathrm{kcal} / \mathrm{mol}$.

\section{REFERENCES}

[1]. T.S. Thorat, V. M. Yadav, G. D. Yadav, Appl. Catal. A Gen. 90, 1992, p. 73.

[2]. G. D. Yadav, N. Kirthivasan, J. Chem. Soc. Chem. Commun. 1995, p. 203.

[3]. G. D. Yadav, V. V. Bokade, Appl. Catal. A Gen. 147, 1996, p. 299.

[4]. G. D. Yadav, T. S. Thorat, Ind. Eng. Chem. Res. 35, 1996, p. 721.

[5]. R.W. McCabe, "Clay Chemistry, in Inorganic Materials", ed. by D.W. Bruce, D. O’Hare (John Wiley \& Sons, Chichester, 1992), pp. 296-351

[6]. J. M. Adams, K. Martin, J. Incl. Phenom. 5, 1987, p. 663.

[7]. J. H. Purnell, "Pillared Layered Structures, in Current Trends and Applications", ed. by I.V. Mitchell (Elsevier Applied Science, New York, 1990), p. 107

[8]. C. Breen, F. D. Zahoor, J. Madejova, P. Komadel, J. Phys. Chem. B 101, 1997, p. 5324.

[9]. P. Komadel, M. Janek, J. Madejova, A. Weekes, C. Breen, J. Chem. Soc. Faraday Trans. 93, 1997, p. 4207.

[10]. T. Alemdaroglu, G. Akkus, M. Onal, Y. Sarikaya, Turk. J. Chem. 27, 2003, p. 675.

[11]. J. Temuujin, Ts. Jadambaa, G. Burmaa, Sh. Erdenechimeg, J. Amarsanaa, K.J.D. MacKenzie, Ceram. Intl. 30, 2004, 251.

[12]. B. Vijayakumar, N. Mahadevaiah, Gopalpur Nagendrappa, B. S. Jai Prakash, J Porous Mater, 19, 2012, p. 201.

[13]. Vijaykumar B., Nagendrappa G., Jai Prakash B. S., Catal Lett., 128, 2009, p. 183.

[14]. M. Galambos, A. Krajnak, O. Rosskopfova, E. Viglasova, R. Adamcova, P. Rajec, J Radioanal Nucl Chem, 298, 2013, p. 1031.

[15]. Adnan Ozcan, Cigdem Omeroglu, Yunus Erdogan, A. Safa Ozcan, Journal of Hazardous Materials, 140, 2007, p. 173.

[16]. Yonggui Chen, Chunming Zhu, Yanhong Sun, Huiying Duan, Weimin Ye, Dongbei Wu, J Radioanal Nucl Chem, 292, 2012, p. 1339., DOI 10.1007/s10967-012-1612-6

[17]. Limei Zhou, Hua Chena, Xiaohui Jiangb, Fang Lua, Yafen Zhou, Wenmin Yinb, Xiaoyang Ji, Journal of Colloid and Interface Science, 332, 2009, p. 16.

[18]. G. D. Yadav, M. B, Thathagar, Reactive \& Functional Polymers, 52, 2002, p. 99.

[19]. G. D. Yadav, M. S. M. Mujeebur Rahuman, in: V. Murugesan, B. Arabindo, M. Palanichamy (Eds.), Recent Trends in Catalysis, Narosa Publishing House, 1999, p. 453.

[20]. P. K. Dubey, S. M. G. Mohiuddin, D. Ramesh, Asian J. Chem. 9(3), 1997, p. 379.

[21]. L. Jakubowwicz, J. Wasilcwski, W. Boruk, Pol. Pat. 102988 C.A.: 94 (1981) 209793]..

[22]. B. Makoto, N. Teruyki, F. Takao, Japan Kokai Pat. 7753802 [C.A.: 88 (1977) 120809j].. 
[23]. H.M. Jaung, J. Ind. Chem. 1988, 266.

[24]. Shaswat Barua, Nipu Dutta1, Sanjeev Karmakar, Pronobesh Chattopadhyay, Lipika Aidew, Alak K Buragohain and Niranjan Karak, Biomed. Mater. 9, 2014, p. 1.

[25]. G. Coudurier and F. Lefebvre, "Catalyst Characterization-Physical Techniques for Solid Materials", edited by B. Imelik and J.C. Vedrine (Plenum, New York, 1994), p. 11.

[26]. Yao Y. Z., Kawi S., J. Porous Mater., 6, 1999, p. 77.

[27]. Behzad Aghabarari, Nasim Dorostkar, Journal of the Taiwan Institute of Chemical Engineers, 45(4), 2014, p. 1468.

[28]. Zahra Darvishi, Ali Morsali, Ultrasonics Sonochemistry, 18, 2011, p. 238. 